\section{REALISM AND RESPECT}

\author{
Kent Baldner \\ Eastern Illinois University
}

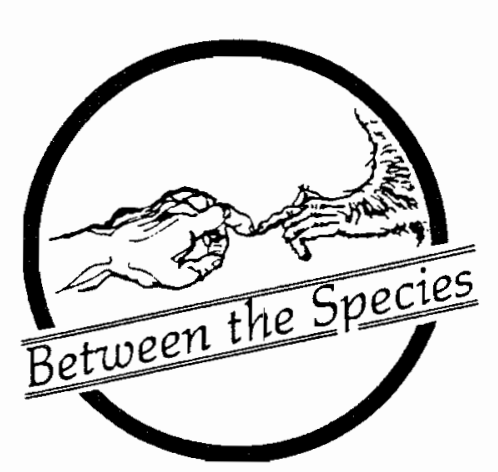

The main thrust of this argument, which Sapontzis calls the "Predation Reductio," is that an obligation to prevent or alleviate animal suffering would entail an obligation to prevent or alleviate natural predation. But this would be absurd, and so we must conclude that we do not have a moral obligation to prevent or alleviate unjustified animal suffering. Sapontzis is willing to concede that an obligation to prevent natural predation does follow from his account of our moral obligations to animals (at least when doing so would not cause as much or more suffering than it would alleviate) but seeks to block the reductio by denying that such an obligation would be absurd. Before I look at Sapontzis' defense of this claim, let us consider whether this kind of obligation can be made out on any other account of our obligations to animals.

It seems clear that such an obligation can be made out along utilitarian lines. Obviously, animals are capable of suffering. The strength of an argument like Peter Singer's ${ }^{3}$ stems from the fact that it acknowledges this fact, and so concludes that the pain and suffering of animals must be taken into account when calculating the over-all utility of some deed. But it is equally obvious that being pursued, attacked, and eaten can cause pain and suffering in the animal pursued. So, from the utilitarian point of view, the only real question is whether or not we can alleviate any of this pain and suffering without in

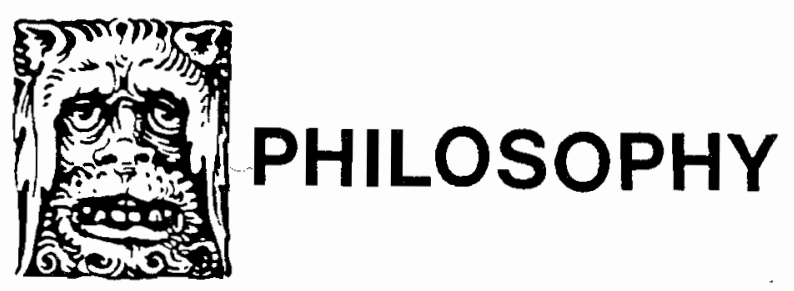

A1: Suppose that humans were morally obligated to alleviate avoidable, unjustified animal suffering.

A2: Innocent animals suffer when they are preyed upon by other animals.

A3: It would follow that humans are morally obligated to prevent predation.

A4: But an obligation to prevent predation would be absurd.

A5: Therefore, contrary to hypothesis, humans are not morally obligated to alleviate avoidable, unjustified animal suffering. 
the process causing even more. I will just assume that this is so. This does not imply that we could achieve a lessening of over-all suffering in every case, but only that were we to intervene in thoughtful ways, we could alleviate some over-all pain and suffering. But even if we could not effectively lessen the total amount of pain and suffering by intervening in any specific case, we would still be obligated to do so if we could. Thus, it seems clear that an obligation to prevent at least some natural predation can be made out on utilitarian lines.

A similar obligation can be derived from the sort of non-utilitarian position that Tom Regan advances in "The Case for Animal Rights." Suppose we posit some kind of "inherent value" in all conscious things--i.e., in everything that is "the experiencing subject of a life. ${ }^{15}$ If there is an inherent value in all conscious life, then the taking of such a life would seem to be inherently wrong, regardless of who or what takes the life. One might object that even if conscious life is inherently valuable, there remain circumstances where taking a life is morally justifiable, and the taking of conscious life involved in natural predation is one of these circumstances. But the scope of this objection is limited. If killing for food is morally justifiable for natural predators, the same should be true for human predators, whether they are individual hunters or corporate factory farmers. By the same token, if predation by humans involves a moral wrong, then so does predation by animals, and so the objection is irrelevant to any account that denies that humans are morally justified in killing animals for food. Consequently, an obligation to prevent natural predation can be derived from at least some nonutilitarian ethical theories.

None of this would imply, of course, that we must hold animal predators morally responsible for taking the lives of other animals. As Sapontzis correctly points out, we can separate our moral judgement of an act from our moral judgement of the actor. Consider our judgements concerning children and the criminally insane. While we do not hold these individuals morally culpable for their behavior, we can still characterize their behavior (tormenting cats, for example) as morally wrong. ${ }^{6}$ Consequently, we can take the same attitude with respect to animal predators. They are simply like "children" in this regard, in that they do not appreciate the moral significance of their behavior. So, even if we cannot condemn natural predators, we can still claim that there is something at least morally regrettable in natural predation.

While there is much that is of interest in Sapontzis' discussion, what I want to focus on is his claim that an obligation to prevent predation would not be absurd. Sapontzis considers several varieties of absurdity and concludes that an obligation to prevent predation is not absurd on any of them. The claim that we ought to prevent some predation is not inconsistent with any of the basic principles of reasoning, nor with any observed fact, and so the obligation is neither logically nor factually absurd. Furthermore, it is not "contextually" absurd, in that it does not violate the context or "spirit" of any of the premises that entail it. (At least not if we add the proviso that we are obligated to prevent predation only if we can do so without causing as much or more pain and suffering than we would be alleviating. $)^{\top}$ Finally, Sapontzis argues that such an obligation would not be "theoretically absurd." To be theoretically absurd, a claim would need to be "inconsistent with some well-supported, thoroughly accepted theory, the principles of which seem much less questionable than the hypothesis from which the offending conclusion derives." ${ }^{18}$ Sapontzis considers a number of different ethical theories and concludes, with one exception, that for none of them would this obligation be absurd.

The one exception that Sapontzis allows is precisely the kind of ethical theory that I am interested in here. An obligation to prevent predation would be absurd if one adopted the kind of ethical theory attributed to Aldo Leopold viz., that "a thing is right when it tends to preserve the integrity, stability and beauty of the biotic community, [and] wrong when it tends otherwise."' Assuming that natural predation "tends to preserve the integrity, stability and beauty of the biotic community," preventing it would thus be inconsistent with the tenets of such a theory. But this fact need not bother us, according to Sapontzis, as this principle is not as "well supported" or "thoroughly acceptable" as are the premises that entail the obligation to prevent predation. "Indeed," Sapontzis continues, "that 
environmental principle is so contrary to paradigm ethical principles ... that it is much more likely to be the object of a theoretical reductio than the basis for one." ${ }^{10}$

It is at this point that I must object. I think that Sapontzis has put his finger on exactly the right issue but has the reasoning just backwards. Clearly, both of the principles in question are counter-intuitive. I will grant that "the environmental principle," as Sapontzis calls it, is initially hard to swallow, but the same must be said of the purported obligation to prevent predation. Indeed, Sapontzis at least implicitly accepts this when he recognizes the need to defend this obligation against the charge of absurdity. Given the incompatibility of the two principles, the question for us now is which to accept and which to reject.

I claim that an obligation to prevent natural predation is morally absurd. By claiming that it is morally absurd, I mean to say that it is inconsistent with a deep-seated moral conviction-viz., that the human species is but one part of a self-sustaining, vastly complex and interconnected system of living and non-living things, and that the total value of this integrated whole cannot be dependent upon any single part of it. If the existence of the natural environment is not dependent upon us, neither is its value: if it does not exist because of us, neither does it exist merely for us. If we adopt an ecological and evolutionary account of the world in which we live, then humanity is not the "end" of creation but merely one part of an interdependent ecosystem that existed before us and will presumably (and hopefully!) exist after us. If we view that interconnected and interdependent system as a kind of "machine," then we are but "cogs" in that "machine" and not the "owners" or "operators" who can "use it" for whatever purposes or ends we see fit.

It strikes me that there is a kind of arrogance in the idea that we even might have an obligation to prevent natural predation. It is as if we were saying that the animal kingdom is inherently immoral, since it is based upon practices that are morally wrong, and that it is up to us to right these wrongs. I am reminded of western missionaries who feel it is incumbent upon them to "save the souls" of aboriginal peoples. The attitude is the same in both cases; viz., that the "primitive" practices of these "heathens" or "dumb brutes" is morally unacceptable, and so it is up to us, who are "enlightened" and "know-better," to set them straight. The paternalistic attitude is the same and the arrogance is the same. Furthermore, this same attitude must actually apply to the environment as a whole. After all, the entire ecosystem is based upon this "balance of nature" where living things compete with one another for limited resources and where, with the exception of plant life, to be a living thing entails consuming other living things. Animal predation is just one instance of this larger pattern, and so it must be that there is something morally improper about the very fabric of the natural environment. It strikes me that this view of things is not only morally absurd, it is morally repugnant.

These are strong words. I am not, however, attributing this kind of arrogance to Sapontzis or to any others who advance a moral theory that can be shown to entail this kind of obligation. Rather, I am trying to make clear why I think there is something fundamentally wrong with any moral theory that entails such an obligation. Obviously, there is a substantial disagreement here. Let us sce if we can uncover its source.

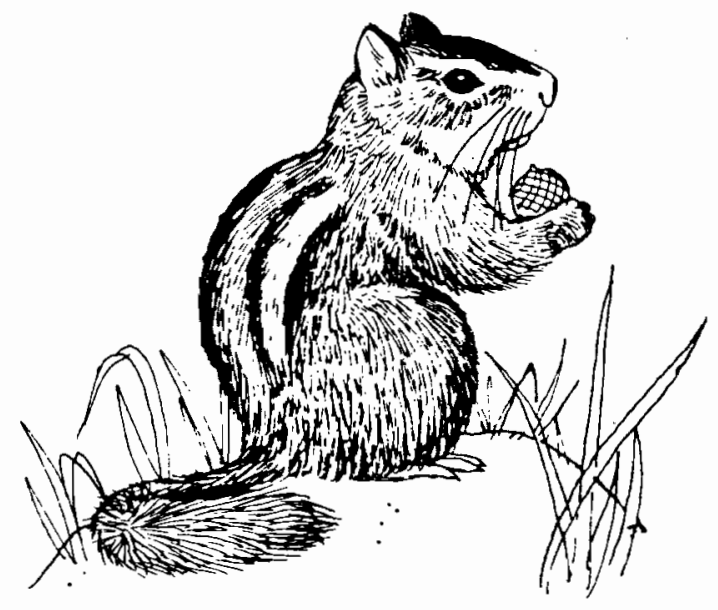


In the last chapter of Morals, Reason, and Animals, Sapontzis examines the kind of environmental ethic considered above and finds it wanting--indeed, he has real doubts about whether it can be classified as a moral philosophy at all." Since Sapontzis finds this environmental ethic to be so obviously less acceptable than an obligation to prevent predation, it will be helpful to look at Sapontzis' criticism of it.

One of the two views that Sapontzis criticizes, and the one I will focus on here, is the position advanced by $\mathrm{J}$. Baird Callicott. ${ }^{12}$ Callicott openly accepts the sort of environmental ethics suggested by Leopold. That is, he accepts "the extension of direct ethical considerability from people to nonhuman natural entities.. ${ }^{13}$ The "land ethic," as Callicott calls it,

is holistic in the sense that the integrity, stability, and beauty of the biotic community is its summum bonum.... Modern ethical theory has consistently located moral value in individuals, ... while environmental ethics locates ultimate value in the "biotic community" and assigns differential moral value to the constitutive individuals relatively to this standard. ${ }^{14}$

Thus the position that Callicott is advancing suggests a kind of "ethical holism" that finds intrinsic moral value in the biotic community as a whole, and assigns moral value to individuals only derivatively, given their place in this community.

But Sapontzis is not moved. Land "ethicists," Sapontzis argues,

want to deny that nonsentient entities have value only as instruments for sentient beings and to affirm that such entities have goods or interests of their own that we ought (morally) to respect. It is doubtful that this affirmation can (logically) be defended. ${ }^{15}$

And to the ethical holism described above, Sapontzis responds:

... [T] $[$ here is no moral reason for adopting total holism. The common moral goal of reducing the suffering in life and otherwise making life more enjoyable and fulfilling would not obviously be more effectively pursued by valuing individuals only as contributors to a community. Indeed, since it is individuals, not communities, that experience enjoyment, fulfillment, distress, and frustration, ... it seems reasonable to conclude that total holism would not provide as likely a path to this moral goal as our current ...morality.... ${ }^{16}$

These (and other ${ }^{17}$ ) remarks suggest that Sapontzis has not fully grasped the radical nature of the change in our attitudes that is being proposed. Sapontzis argues that "there is no moral reason for adopting total holism" and that it is doubtful that there is any way to defend the claim that nonsentient natural entities can have a kind of value apart from their value as instruments for sentient beings. But as I see it, what is being proposed is a wholly new way of looking at what constitutes a "moral reason." What is being suggested is a reassessment of the moral goals or values on the basis of which various moral claims can be logically defended. Thus, it seems that Sapontzis is criticizing the environmentalist position because it cannot be shown to follow from the existing "moral reasons" or "moral goals," when what is being proposed is a change in those very moral reasons and goals.

The land ethic, once again, claims that there is some kind of non-instrumental moral value in the environment as a whole, and that, consequently, we must grant direct moral status even to nonsentient parts of that environment. It is tempting--but, I believe, mistaken--to view this as the suggestion that we must "widen" the domain of things that have moral standing. This "broadening" of the moral sphere could then be understood as analogous to the kind of broadening proposed by those who would have us extend moral standing to all sentient creatures. Thus, it is tempting to see the environmentalist position as the latest in a series of proposed expansions of the moral realm, parallel to the "expansions" that recognized the moral standing of women and non-whites.

But this would be a mistake. The proposal is 
not that we bring more individuals into the "fold" but that we reject the idea that individuals are the sorts of things that have intrinsic moral worth. The claim is not that trees and rivers have the same sort of intrinsic moral standing as do human beings, or other sentient beings, but that trees, rivers, human beings and animals alike have a moral standing derived from the value of the environment as a whole. While it is clear from his characterization of ethical "holism" that Sapontzis understands that this is what Callicott and others are proposing, the kinds of criticisms he makes of this proposal suggest that he has not fully grasped what this entails. If what counts as having moral standing is to be changed, this will entail a change in what will count as the "goals" of morality and what will count as a moral reason. If the foundations or "beginnings" of morality are to be altered, so must be its "ends." Thus, it is a mistake to criticize ethical holism on the grounds that it is not an effective means of achieving the "moral goal of reducing suffering and otherwise making life more enjoyable and fulfilling...." If we accept ethical holism, then this goal is no longer an ultimate goal of morality but must be understood in terms of its value to the environment as a whole. To criticize the environmentalist position on these grounds is to criticize it for failing to meet up to a set standard that it explicitly rejects. It is not surprising, then, that one would find "no moral reason for adopting total holism" if what one counts as a moral reason is deeply embedded in a moral theory that is fundamentally opposed to this kind of holism.

What is being proposed by the environmentalists, then, is something akin to a "paradigm shift" in moral philosophy. We must therefore recognize, as with any proposed shift in theoretical paradigms, that from the standpoint of the "established" paradigm, the claims of the "new" paradigm will seem ridiculous or, worse yet, to be concerned with some other topic altogether. (Recall Sapontzis' doubts about "whether environmental holism is itself a moral philosophy at all.") But of course, to note the radical nature of the change being proposed is not to defend the need for such a change. For the remainder of this paper, I will address some of the reasons for accepting this change in ethical paradigms.

As I see it, the primary impetus for granting direct moral standing to the natural environment as a whole stems from a belief in the metaphysical independence and reality of the natural world. If one takes seriously the idea that the planet we live on has existed for billions of years prior to the existence of any human being, and that human beings themselves have evolved as one part of a vastly complex, interconnected, and interdependent ecosystem, it is difficult to avoid the conclusion that human beings are not the center of the universe--that man is not the measure of all things.

But what follows from this insight? One thing that follows is that we should be able to apply to human behavior the same sorts of "naturalistic" explanations that we apply to animal behavior. If one looks at the behavior of animals in an ecologically sensitive way, one tends to see that behavior in terms of its purpose or function in the wider ecological economy. Thus predators often attack only the weak or the sick, thereby contributing to the over-all strength and health of the population preyed upon. And this, in turn, will insure that in the future, only the strongest and healthiest predators will be able to hunt successfully. Of course, the individual predator has none of this "in mind." Presumably, they attack the weak and sick because this is easier, or simply because it is only the weak or the sick they can catch. Consequently, we can see ecological purpose or function even when this is hidden from the animal itself. Likewise, the "protective instinct" evidenced by mammals towards their immature offspring has direct evolutionary value, given that mammals are typically born without the skills or defenses necessary to support or protect themselves. But once again, the mammalian mother knows nothing of this evolutionary design, although she presumably (and apparently) feels some direct bond with her young, or simply defends them instinctually. Again, we see the evolutionary value, even if the animal does not. In each case, it seems, what has evolutionary or ecological value is whatever it is in the animal that causes or motivates it to act in these ways.

My suggestion is that these same kinds of explanations can be applied to human behavior, and, more specifically, to human values. Thus, the things we find pleasurable (e.g., eating, sex, companionship) can be explained in terms of their 
evolutionary value. Likewise with the things that cause us pain. Callicott thus ridicules as "biologically preposterous" the utilitarian doctrine that "life is the happier the freer it is from pain and that the happiest life conceivable is one in which there is continuous pleasure uninterrupted by pain...." ${ }^{18}$ To view pain as intrinsically evil is to lose sight of the fact that it conveys "important organic information." ${ }^{\prime \prime}$ But while there is something to Callicott's criticism, it seems that he, too, has missed the point. Callicott is correct in calling attention to the evolutionary value of the experience of pain. But what he apparently fails to grasp is that what has evolutionary value is not pain or pleasure itself but the fact that individual humans and other sentient creatures value pleasure and seek to avoid pain. What is important is what we do in order to maximize pleasure and minimize pain. Consequently, it is the fact that we have the individual and social values that we do that serves an evolutionary or ecological function by motivating us to behave in certain ways. In short, we can give evolutionary or ecological explanations for why we have the moral values that we do. But if we take these evolutionary explanations seriously, we must accept that the moral paradigm with which we have been operating has its basis or foundation in a "deeper" system of values.

Thus, one reason for changing ethical paradigms is that if we take these evolutionary and ecological explanations seriously--as I think we should--we can see the role or function of our existing moral values in a larger context. We can see that they serve a larger purpose, and that, consequently, their value is not intrinsic but derives from their "place" in this larger context. But the only way I know of to account for this "deeper" set of intrinsic values is to posit direct moral standing in the natural environment itself.

One may question, at this point, the appropriateness of calling this "deeper" value a moral value at all. That is, one may doubt, as does Sapontzis, whether this kind of ethical holism really merits being called a moral philosophy at all. After all, as Sapontzis claims, "[s]ignificant moral criticism must (logically) be based, at least in part, on our currently accepted moral principles or values. ${ }^{\prime 20}$ But is there anything in what $I$ am suggesting that is in the least bit similar to our "currently accepted moral principles or values?"

I think that there is. One has to be careful, of course, in placing too much emphasis on current moral values, or one will end up arguing that moral criticism is impossible a priori. Clearly, the claim that we have significant moral obligations to animals stands opposed to our current moral principles, if the latter are defined narrowly enough. With respect to any moral criticism, we must be able to appeal to some kind of fundamental moral principles on which we can base our criticism, if we wish to claim that they are indeed moral criticisms. What fundamental principles or insights can the environmentalist appeal to that will be recognized as moral principles and moral insights?

Let me suggest one. I think my sense that there is something arrogant in the claim that we have a moral obligation to prevent natural predation is based upon a fundamental moral sentiment that it is improper to place too much emphasis or importance upon oneself, especially if the facts do not bear out this evaluation. It strikes me that there is something morally perverse in believing that we are in any position to make moral judgements concerning the very fabric of the world that has given us existence. It is a sign of hubris to think that the natural environment is simply ours to do with as we like, and that it has value only because of us, even though we have existence only because of it. Given our relatively small place in the grand scheme of things, it is unacceptably anthropocentric to think that the nonsentient parts of the environment have value only because we bestow it upon them.

But Sapontzis will argue that his "animal liberationist". ethic can account for the natural environment having a value over and above its usefulness to human beings. In addition to its value for human beings, we must, according to Sapontzis, recognize its value for other sentient beings. ${ }^{21}$ This would allow us to find value in the environment that is not directly tied to its instrumentality to human beings and would thus apparently avoid the charge of anthropocentrism leveled above.

This raises a fundamental question. Is the natural environment to be valued because of its usefulness to sentient creatures, or because it is the foundation of sentience and of life itself-- 
because it is the metaphysical ground of all that has value? Sapontzis apparently opts for the first alternative, while I am inclined towards the second. To answer this question we must ask ourselves why it is that sentience is so important. The first alternative apparently finds intrinsic value in sentience itself and can thus recognize value in nonsentient things because of their instrumentality for sentient creatures. But while this account recognizes that sentient beings are not of value simply because they are of some use to human beings, it apparently grants them independent value because they are similar to human beings. The extension of direct moral standing to all sentient creatures seems to be based upon the following line of reasoning: we recognize the intrinsic value of pleasure and of living a happy and fulfilling life, and also the intrinsic evil of pain and suffering, and so, to be consistent, grant direct moral standing to creatures whose experiences are similar to ours in these respects. We grant them direct moral standing because they are like us--because they feel what we feel.

But isn't this also anthropocentric? In this case, it seems we are assigning moral status to a thing on the basis of its relation to us. This still places human beings at the conceptual center of the moral universe. It allows that there are beings other than human that have direct moral standing, but it defines the properties a thing must have in order to have this standing in terms of a similarity to human beings. What I wish to suggest is that we grant moral standing not on the basis of a thing's relation to us but recognize, instead, that perhaps we have moral standing because of our relation to something else. Thus, even the animal liberationist's claim that the value of the natural environment can be understood in terms of its usefulness to sentient beings is open to the charge of moral anthropocentrism.

Is there any other fundamental moral insight the environmentalist can appeal to in order to buttress the claim that nonsentient things can have direct moral standing? In closing, I would suggest we examine our shared experience of the value of the natural environment. More than one of the philosophers mentioned here speaks of a feeling of moral respect for nonsentient parts of the environment. This certainly describes my own experience when hiking through the woods or when "face to face" with a massive redwood that is thousands of years old. But even those who would not characterize this experience as one of moral respect often recognize the "psychological renewal value ${ }^{\prime 22}$ of a trip to the country. There is a common experience, if not a common understanding, of the value of the natural world, and we should not underestimate the importance of this shared experience. I see this value as a moral value and characterize the experience as one of reverence and respect for that which is the basis of all that has value.

Notes

1. Most of these people owe some debt to the work of Aldo Leopold. See his A Sand County Almanac (New York: Oxford University Press, 1966) and "Some Fundamentals of Conservation in the Southwest." published posthumously in Environmental Ethics 1 (1979): 131-141. Current philosophers who adopt a similar view include the following: J. Baird Callicott in "Animal Liberation: A Triangular Affair," Environmental Ethics 2 (1980): 311-338, and "Reply to Sapontzis," Ethics and Animals 5 (1980): 135-139. Michael W. Fox. "Man and Nature: Biological Perspectives," and What Future for Man and Earth?: Towards a Biospiritual Ethic." both in R.K. Morris and M.W. Fox, eds., On the Fifth Day: Animal Rights and Human Ethics (Washington, D.C.: Acropolis Books ed.. (1978): 111-127 and 219-230 respectively; Kenneth Goodpaster, "On Being Morally Considerable," Journal of Philosophy 75 (1978): 308-325, and "From Egoism to Environmentalism," in K.E. Goodpaster and K.M. Sayre, eds., Ethics and Problems of the 21st Century (Notre Dame: Notre Dame University Press, 1979): 21-35: Tom Regan. "The Nature and Possibility of an Environmental Ethic," Environmental Ethics 3 (1981): 19-34, All That Dwell Therein (Berkeley: University of California Press, 1982), and The Case for Animal Rights (Berkeley: University of California Press, 1985): John Rodman, "The Liberation of Nature?," Inquiry 20 (1977): 83-131, and "Animal Justice: The Counter-revolution in Natural Right and Law." Inquiry 22 (1979): 3-22: and Holmes Rolston III. Philosophy Gone Wild (Buffalo, New York: Prometheus Books. 1986), and Environmental Ethics (Philadelphia: Temple University Press. 1988).

2. Morals, Reason, and Animals. (Philadelphia: Temple University Press. 1987): 229.

3. Peter Singer. Animal Liberation. (New York: Avon Books. 1975).

4. This is included in In Defense of Animals. I am not clear that this represents Regan's current view. In any event. what 
I am trying to show is only that an obligation to prevent predation can be given a non-utilitarian foundation.

5. The Case for Animal Rights, p. 325 .

6. Morals, Reason, and Animals, p. 231.

7. Ibid., pp. 233-234.

8. Ibid., p. 234 .

9. Ibid., p. 235. Sapontzis is quoting from Aldo Leopold, $\underline{A}$ Sand County Almanac, pp. 224-225.

10. Morals, Reason, and Animals, p. 235.

11. Ibid., p. 265.

12. "Animal Liberation: A Triangular Affair." p. 311-336.

13. Ibid. p. 312

14. Ibid.. pp. 311 and 337.

15. Morals, Reason, and Animals, p. 268.

16. Ibid., p. 263.

17. Sapontzis makes similar remarks throughout pp. 262-267 of Morals, Reason, and Animals.

18. "Animal Liberation: A Triangular Affair," p. 333.

19. Ibid.

20. Morals, Reason, and Animals, pp. 264-265.

21. Ibid., p. 271

22. This phrase is Sapontzis'. See Morals, Reason. and Animals. p. 269.

\section{ENVIRONMENTAL ETHICS AND THE LOCUS OF VALUE}

\author{
S. F. Sapontzis \\ California State University, Hayward
}

In "Realism and Respect," Professor Baldner attempts to defend holistic environmental ethics against criticisms I made of it in my book, Morals, Reason, and Animals (Philadelphia: Temple University Press, 1987). While I very much appreciate the care Professor Baldner has given to accurately stating and thoughtfully critiquing my views, I do not find that critique compelling for the following reasons.

First, the fundamental, theoretical flaw in environmental ethics of the sort Baldner advocates is the belief that values can exist without reference to the capacities of sentient beings. The prevalence of this mistaken belief among environmental ethicists may be due to the use of "value" in phrases like "its value for evolution." In such phrases "value" refers to the role played by something in evolution. This role can be completely explicated in non-evaluative descriptions of how this thing interacted with other things to contribute to the course of evolution. That this can be done shows that the term is being used non-evaluatively in such phrases. Where evaluation enters here is in the presumption that the course or products of evolution are good, fulfilling a purpose, or otherwise worthy. That is a value something has not merely "for evolution" but for a sentient being contemplating evolution.

Baldner attempts to support his value theory by contending that "if the existence of the natural

\section{A Reply to Kent Baldner's "Realism and Respect"}

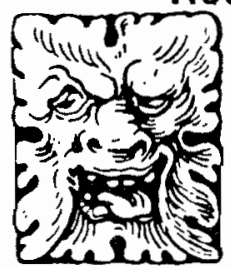

